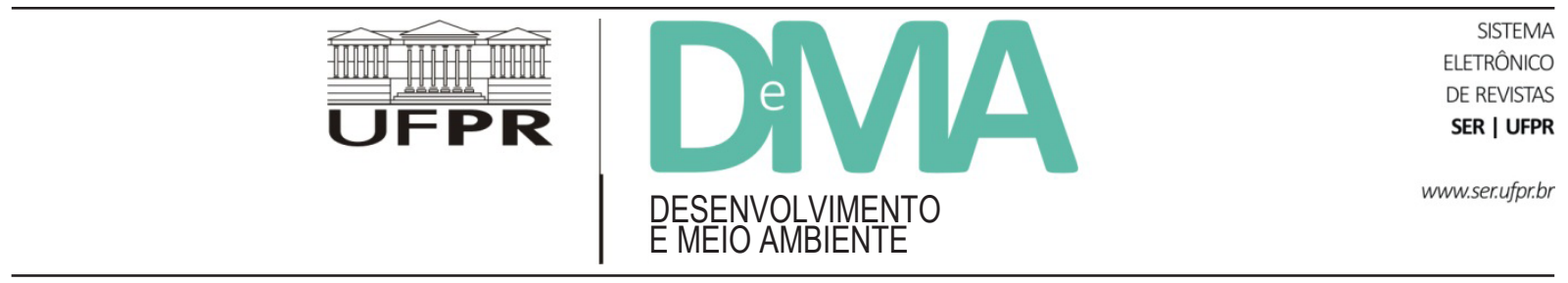

\title{
La Comunidad Zona Lacandona y las áreas naturales protegidas en su territorio
}

\section{A comunidade de Zona Lacandona e as áreas naturais protegidas em seu território}

\section{The Lacandon Community and the Protected Natural Areas in its Territory}

\author{
Héctor CALLEROS-RODRÍGUEZ ${ }^{1 *}$, Maria Lourdes GUEVARA-ROMERO² \\ ${ }^{1}$ Investigador Invitado. Instituto de Relaciones Internacionales, Universidad de Varsovia, Polonia. \\ ${ }^{2}$ Benemérita Universidad Autónoma de Puebla, Puebla, México. \\ *E-mail de contacto: hcalleros.coltlax@gmail.com
}

Artículo recibido el 23 de febrero, 2016, versión final aceptada el 5 de julio, 2016.

RESUMEN: Este artículo analiza la compleja relación entre el hombre y la naturaleza. En particular, analiza los problemas que presentan las Áreas Naturales Protegidas (ANP), que existen dentro de tierras indígenas. El artículo plantea dos hipótesis: i) la existencia de ANP en la Selva Lacandona es el producto de la política ambiental mexicana que, durante cuarenta años, ha configurado a la selva como una región de conservación de la biodiversidad, sin embargo, esa política genera relaciones de poder en las zonas en que opera. ii) La relación hombre - naturaleza, que en este artículo se refiere a la relación entre la comunidad indígena (Comunidad Zona Lacandona) y las ANP, presenta tensiones que surgen del tamaño y necesidades de las poblaciones que habitan dentro de las áreas, más que de relaciones de poder. Con base en un análisis del cambio de uso de suelo y del crecimiento poblacional, el artículo presenta datos actuales que confirman el continuo deterioro de la cobertura forestal. El artículo también se basa en trabajo de campo realizado en la Selva Lacandona en los años 2008, 2010 y 2015.

Palabras clave: uso de suelo; áreas naturales protegidas; México; Comunidad Zona Lacandona.

RESUMO: Este artigo analisa a complexa relação entre o homem e a natureza. Analisa, sobretudo, os problemas apresentados nas Áreas Naturais Protegidas (ANP) localizadas em territórios indígenas. O artigo levanta duas hipóteses: i) a existência de ANPs na Selva Lacandona é produto da política ambiental mexicana que, durante quarenta anos, havia definido a selva como uma região de preservação da biodiversidade, porém, tal política ambiental gera relações de poder nas áreas em que atua; ii) a relação homem-natureza, que neste artigo se refere à relação entre a comunidade indígena (Comunidade Zona Lacandona - CZL) e as ANPs, apresenta as tensões que surgem devido ao tamanho e às necessidades das populações que vivem nessas áreas, mais que 
das relações de poder. Com base em uma análise da alteração do uso do solo e do crescimento populacional, o artigo apresenta dados atuais que confirmam a deterioração da cobertura florestal. O artigo é baseado nas pesquisas de campo realizadas na Selva Lacandona nos anos de 2008, 2010 e 2015.

Palavras-chave: uso do solo; áreas naturais protegidas; México; Comunidade Zona Lacandona.

ABSTRACT: This article analyses the complex relationship between humans and nature. In particular, it analyses some of the problems that Protected Natural Areas (PNAs), located within Indigenous lands, present. The article formulates two hypotheses: i) the existence of PNAs in the Lacandon Forest is the outcome of an environmental policy that has shaped the forest as a region for biodiversity conservation; however, this policy generates power relations in the regions where it operates. ii) The relationship between humans and nature, that in this article is examined as the relationship between the indigenous community (Lacandon Community) and the PNAs, exhibits tensions that population size and needs bring forth; power structures are secondary. Based on an analysis of land uses changes and population growth, the article presents fresh evidence that confirms the continued deterioration of forest cover. The article is also based on field work conducted in the Lacandon Forest in the years 2008, 2010 and 2015.

Keywords: land use; protected natural areas; Mexico; Lacandon Community.

\section{Introducción}

La Comunidad Zona Lacandona (CZL) se encuentra en una región que ha sido destino de contradictorias políticas de uso de los recursos naturales. Si la reforma agraria convirtió a la Selva Lacandona en el destino de pequeñas sociedades agrarias (ejidos), la política ambiental, la configuró como una región de conservación. Muchas otras políticas más han operado en la región, incluyendo programas de salud, educación, asistencia social y estímulo productivo.

La CZL es una comunidad agraria e indígena, creada por la reforma agraria mexicana; tiene 16,794 habitantes (Figura 1). En su territorio alberga a dos localidades urbanas (Nueva Palestina y Frontera Corozal), dos reservas de biosfera (Montes Azules y Lancan-Tún), siete áreas protegidas (Figura 2 y Tabla 1), dos monumentos naturales (Yaxchilán y Bonampak) y tres áreas de protección de flora y fauna (Najá, Metzabok y Chan-Kín). La CZL es el producto de dos resoluciones presidenciales en materia agraria (Calleros-Rodríguez, 2013).
La primera resolución fue publicada el 6 de marzo de 1972 (Reconocimiento y Titulación de Bienes Comunales). Bajo este procedimiento, 66 jefes de familia de la etnia Lacandona recibieron 621,324 hectáreas de tierra en la Selva Lacandona. La segunda resolución presidencial data del 8 de marzo de 1979 (Resolución Presidencial sobre Reconocimiento de Derechos Agrarios Comunales en el núcleo de población denominado Zona Lacandona) reconoció los derechos agrarios de 1452 comuneros de las etnias Tseltal y Chol. Las colindancias de esta comunidad han sido fuente de problemas de tenencia de la tierra por más de cuatro décadas (Calleros-Rodríguez, 2014; Ascencio, 2008).

Este artículo parte del supuesto de que los cambios en el uso del suelo (CUS), en el territorio de la CZL, permiten entender la relación medio ambiente y sociedad y que la población local (comuneros) usa los recursos naturales de su entorno. El artículo examina dos variables: el crecimiento poblacional en el periodo 1990- 2015 y los CUS que han ocurrido en las Áreas Naturales Protegidas (ANP) localizadas en el territorio de la CZL, en los 
años 1990 y 2013. La metodología del artículo es mixta: los datos provienen de cartografía del Instituto Nacional de Estadística y Geografía (INEGI) y del Sistema de Información, Monitoreo y Evaluación para la Conservación (SIMEC). El cambio de uso de suelo y vegetación en la comunidad de estudio se realizó a partir de dos series de tiempo (Serie II y Serie IV de las cartas de uso de suelo y vegetación del INEGI). El análisis de la información se realizó utilizando Sistemas de Información Geográfica (SIG) para identificar los cambios durante cada periodo; así mismo, para analizar los CUS y cambios de vegetación se realizó un análisis espacial, utilizando el software ArcGIS versión 10.3. En este paquete se agruparon las claves de cada serie, se realizó el cruce cartográfico de las dos series de tiempo analizadas y se hizo la representación de los procesos espacio-temporales; con esto, se generaron los mapas (figuras) cartográficos que expresarán los cambios de la vegetación en las dos series de tiempo ya mencionadas. Además, se realizaron entrevistas a miembros de la CZL (comuneros) y funcionarios de la Comisión Nacional de Áreas Naturales Protegidas (CONANP), en los años 2008, 2010, 2015. También se revisó información gubernamental (legislación, programas, reportes y estudios) sobre las áreas protegidas objeto de este artículo.

\section{La discusión académica sobre la conservación en la Selva Lacandona}

Las ANP resultan de la configuración que la política ambiental mexicana ha hecho, durante cuarenta años, de la Selva Lacandona como región de conservación ambiental. Desde mediados del siglo $\mathrm{XX}$, en la Selva se han ejercido diversas políticas públicas: reparto agrario y colonización, explotación forestal, agricultura y ganadería y conservación ambiental. Estas políticas han establecido relaciones, procesos y estructuras que han condicionado el acceso, tendencia y usos de los recursos naturales a diferentes poblaciones de la Selva.

La literatura académica ha analizado la complejidad y diversidad de los pueblos indígenas en la zona; por ejemplo, Contreras Cortés et al. (2015) y Diemont y Martin (2009) analizan las estrategias de manejo de los recursos naturales de los Lacandones, que tienen un impacto mínimo sobre los ecosistemas. En contraste, en la Selva, otras etnias parecen no tener semejantes prácticas, como lo informan dos estudios sobre el área inmediatamente contigua a la CZL, en la punta suroriental de la selva, Marqués de Comillas - Benemérito de las Américas son Costedoat et al. (2015) y Meli et al. (2015). La literatura también ha analizado la eficacia de las ANP para frenar las tasas de deforestación (Figueroa y Sánchez-Cordero, 2008) y la participación de poblaciones locales en la gestión de los recursos naturales (Legorreta, Márquez y Trench, 2014). Otro tema que ha sido analizado es el de los problemas de legitimidad en la creación de áreas protegidas. Este es un tema sobresaliente, considerando que, en México, la política ambiental se ha establecido y operado, en gran parte, sin considerar a la población local (Legorreta y Márquez, 2014; Bezaury-Creel y Gutiérrez, 2009). Este tipo de estudios argumentan que las relaciones gobierno (sector ambiental) y sociedad (comunidad indígena) están marcadas por la falta de ciudadanía. En consecuencia, la cooperación se complica cuando no hay cultura ni prácticas democráticas entre las autoridades (CONANP) y los dueños de la tierra, la población indígena. Una relación carente de ciudadanía es autoritaria. Sin embargo, esta relación también es ineficaz para aplicar la legislación ambiental (Legorreta y Márquez, 2014; Durand y Figueroa, 2014). Estos estudios señalan que la falta 
de negociaciones y consentimiento en los términos y contenido de la relación es contraproducente para la operación de las ANP y de la política ambiental, en general. Otras investigaciones han identificado diferentes problemas en la operación de reservas de biosfera: Tehuacán-Cuicatlán (Lee 2014), Ría Celestún (Pinkus-Rendón y Pinkus Rendón, 2015), El Vizcaíno (Lagunas-Vázquez et al., 2008) y Mariposa Monarca (Brenner, 2009; Merino y Hernández, 2004).

\section{Las Areas Naturales Protegidas y la Comunidad Zona Lacandona}

En las crecientes complicaciones y constantes cambios que conlleva el manejo de las ANP, la protección de los recursos naturales, se ha basado en principios ecológicos, sin embargo, las pautas de esa relación han reconocido los derechos de ciertas poblaciones, como las poblaciones indígenas, según marcos basados en los Derechos Humanos. La importancia de estos derechos, en el manejo y operación de las ANP, varía.

En México, el gobierno federal, a través de la Comisión Nacional de Áreas Naturales Protegidas (CONANP) opera 177 Áreas Naturales Protegidas (25,628,239 hectáreas), en seis diferentes categorías (CONANP, 2016) -y 369 áreas destinadas voluntariamente a la conservación (404,516.17 hectáreas)-. Las Áreas Naturales Protegidas (ANP) son el principal instrumento de conservación en México; son creadas mediante decretos presidenciales y requieren, entre otras cosas, de un programa de manejo. En complemento con el sistema federal administrado por CONANP, cada estado federal tiene su propio régimen de áreas protegidas. El estado de Chiapas, donde se ubica la CZL, también tiene ANP bajo su jurisdicción, aunque ninguna de ellas se encuentra en la Selva Lacandona.

México también es un actor global en materia de conservación de la biodiversidad; de las cuarenta y una reservas de biosfera (hasta junio de 2014) que tiene registradas en la Red Mundial de Reservas de Biosfera de UNESCO, dos de ellas se ubican en la Selva Lacandona, en las tierras de la CZL: Montes Azules (1977) y Nahá-Metzabok (2010). Por otra parte, de acuerdo con la clasificación del Sistema Nacional de Áreas Naturales Protegidas (SINAP) ${ }^{1}$, en las tierras de la CZL se incluyen Montes Azules (2000), Lacan-Tún (2000), Chan-Kín (2000) y Bonampak (2003) 2 .

Las ANP que existen en la Selva Lacandona son el producto de cuatro décadas de política ambiental mexicana. La política ambiental comprende legislación, instituciones y programas. Por ejemplo, en materia de legislación, la política ambiental deriva de la Constitución: artículo 25 (el estado como motor del desarrollo), artículo 26 (la planeación democrática nacional), artículo 4 (derecho a un ambiente adecuado para el desarrollo humano) y artículo 27 (la nación tiene el derecho de regular, en beneficio de la sociedad, los elementos naturales susceptibles de apropiación para su conservación y un desarrollo equilibrado del país). Una de las leyes más importantes es la Ley General del Equilibrio Ecológico y la Protección al Ambiente (LGEEPA) que establece las reglas de operación de las áreas protegidas y las considera como parte de un régimen de preservación y uso sustentable de la biodiversidad (Azuela et al., 2008; Carmona

\footnotetext{
1 Reglamento de la Ley General del Equilibrio Ecológico y Protección al Ambiente.

$2<$ www.conanp.gob.mx/que_hacemos/sinap.php $>$ [consulta 30 de enero de 2016]
} 
2003). La LGEEPA también crea el Sistema de Áreas Naturales Protegidas (SINAP). Otras leyes regulan el uso de los recursos naturales ${ }^{3}$.

En términos de las instituciones que conducen la política ambiental, su especialización se consolidó a partir de la Cumbre de la Tierra, Río Janeiro (Brasil, 1992). En los años 1970, se estableció una subsecretaría para el mejoramiento del ambiente adscrita a la Secretaría de Salubridad y Asistencia y en los años 1980, se creó la Secretaría de Desarrollo Urbano y Ecología (SEDUE), cuyas funciones fueron transferidas, en 1992, a la Secretaría de Desarrollo Social (SEDESOL) y el manejo de los parques nacionales pasó a la Secretaría de Agricultura y Recursos Hidráulicos (SARH) (Bezaury-Creel et al., 2009). La década de los noventa realmente marca la consolidación de la política ambiental mexicana: en 1992 se creó el Instituto Nacional de Ecología (INE), la Procuraduría Federal de Protección al Ambiente (PROFEPA) y la Comisión Nacional para el Uso y Conocimiento de la Biodiversidad (CONABIO). Después, en 1994, se creó la Secretaría de Medio Ambiente, Recursos Naturales y Pesca (SEMARNAP), encargada de planear el manejo de recursos naturales y políticas ambientales, buscando remediar la degradación ambiental, estableciendo "nuevos instrumentos, políticas y estructuras" (Moctezuma, 2016). Con la creación de SEMARNAP nació también el SINAP, como un elemento esencial de la política ambiental de conservación de la biodiversidad. En el año 2000, se creó la CONANP y SEMARNAT, después de que la anterior SEMARNAP perdiera jurisdicción sobre la pesca.

En términos de política ambiental, diversos instrumentos han dado forma a la Selva Lacandona como una región de conservación. Uno de los instrumentos fundamentales son las $\mathrm{ANP}^{4}$. Sus objetivos son (LGEEPA, Artículo 45) incluyen: asegurar el equilibrio y la continuidad de los procesos evolutivos y ecológicos preservando los ambientes naturales representativos de las diferentes regiones bio-geográficas y ecológicas y de los ecosistemas más frágiles, y también, proteger los entornos naturales de zonas, monumentos y vestigios arqueológicos, históricos y artísticos, así como zonas turísticas, y otras áreas de importancia y de los pueblos indígenas. Las ANP se clasifican en: reservas de biosfera, parques nacionales, monumentos naturales, áreas de protección de recursos naturales, áreas protegidas de flora y fauna, santuarios; parques y reservas estatales, zonas municipales de conservación ecológica y áreas voluntarias de conservación.

Otro instrumento de política ambiental es el Ordenamiento Ecológico del Territorio (Azuela et al., 2008). El Programa de Ordenamiento Ecológico General del Territorio (POEGT) tiene una base constitucional, en la legislación secundaria (LGEEPA) y en los planes nacionales (sexenales)

\footnotetext{
3 La Ley General de Pesca y Acuacultura Sustentables (2007) y el Reglamento de la Ley de Pesca (1999); la Ley de Aguas Nacionales (1992 y 2004) y su Reglamento (1994); la Ley Minera (1992, 1994 y 2005); la Ley General de Vida Silvestre (2000), y la Ley General de Desarrollo Forestal Sustentable (2003).

4 Las ANP son porciones terrestres o acuáticas del territorio nacional representativas de los diversos ecosistemas, en donde el ambiente original no ha sido esencialmente alterado y que producen beneficios ecológicos cada vez más reconocidos y valorados. Se crean mediante un decreto presidencial o través de la certificación de un área cuyos propietarios deciden dedicar a la conservación y las actividades que pueden llevarse a cabo en ellas se establecen de acuerdo con la LGEEPA, su Reglamento, los programas de ordenamiento ecológico y los respectivos programas de manejo. Están sujetas a regímenes especiales de protección, conservación, restauración y desarrollo, según categorías en la Ley.
} 
de desarrollo. La función del POEGT es construir relaciones equilibradas entre ecosistemas, recursos naturales y la sociedad. El POEGT ha dividido a México en 145 Unidades Ambientales Biofísicas (UAB) (ver Bollo et al., 2013), una de ellas es Sierra Lacandón, estableciendo que sea un recipiente de políticas ambientales de protección y preservación y de actividades forestales. El POEGT ha establecido la Región Ecológica 2.17 cuyo significado es que la política para la región debe ser dirigida hacia la preservación de flora y fauna y a actividades forestales deben ser los conductores del desarrollo. Para Sierra Lacandona, el POEGT pronostica para 2033 condiciones inestables y críticas; tiene un nivel de Alta (4/5) prioridad (DOF, 2012). Sierra Lacandona es una sub-provincia fisiográfica en la que hay conflictos ambientales (PO, 2012). Estos planes registran las tensiones que los datos de este ensayo aportan: conflicto entre crecimiento demográfico y áreas de conservación, al Este y Norte de la RBMA. También indica que una de las áreas con posible ocurrencia de conflictos dentro de las reservas son, precisamente, Montes Azules y Lacan-Tún. Igualmente, algunas áreas al este y norte de Montes Azules (PO, 2012). El estado de Chiapas, donde se encuentra la UAB Sierra Lacandón, tiene su propio un programa de Ordenamiento Territorial: Programa de Ordenamiento Ecológico y Territorial del Estado de Chiapas (POETCh). Selva Lacandona (Región XII; municipalidades de Ocosingo y Altamirano) tiene áreas prioritarias para servicios ambientales (fijación de carbono, producción de humus y recarga de acuífero): Montes Azules, Selva El Ocote, La Sepultura y El Triunfo (PO, 2012; Chiapas, 2012). En suma, en términos de ordenamiento territorial, la CZL ha sido clasificada como área de conservación y desarrollo de actividades forestales.

La política ambiental también cuenta con programas orientados a la población que habita áreas bajo conservación: el Programa de Empleo Temporal (PET) orientado a pagar jornales en la construcción de obras de infraestructura física para restauración, manejo y conservación, el Programa de Conservación y Desarrollo Sustentable (PROCODES), antes llamado Programa de Desarrollo

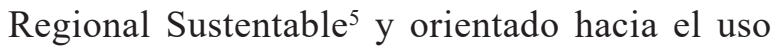
sustentable de recursos naturales en ANP y áreas vecinas. El gobierno 2013-2018 incluyó programas de vigilancia comunitaria y conservación de maíces criollos (Entrevista 81015-Conanp).

Un instrumento más de política ambiental es la cooperación internacional. Por ejemplo, tres instrumentos multilaterales son el programa el Hombre y la Biosfera (UNESCO) ${ }^{6}$, la Convención sobre los Humedales (Convención de Ramsar ${ }^{7}$ ) y la Convención Patrimonio de la Humanidad ${ }^{8}$. La cooperación internacional tiene un ámbito regional, por ejemplo, desde 1994, el Corredor Biológico Mesoamericano es una iniciativa de cooperación centroamericana en la que participan Panamá, Costa Rica, Nicaragua, Honduras, El Salvador,

\footnotetext{
5 Los PRODERS operaron en las ANP con el mayor número de población en situación de pobreza extrema: Montes Azules, Lacan-Tún, Mariposa Monarca, Calakmul, Los Tuxtlas, Manantlán, Isla Tiburón, Sierra Gorda, Yum Balam and Tehuacán-Cuicatlán (SEMARNAP, 2000; Bezaury-Creel et al., 2009).

6 En el programa el Hombre y la Biosfera (UNESCO) en el que México participa con 41 Reservas de Biósfera, de las cuales, dos están dentro de la CZL: Montes Azules (1979) y Najá-Metzabok (2011).

La Convención de Ramsar incluye a 142 sitios de México, incluyendo a las Áreas de Protección de Flora y Fauna Najá y Metzabok.

8 México ha registrado 38 bienes y hecho varias nominaciones: por ejemplo, en 2004 propuso a la Región Lacan-Tún Usumacinta (SEMARNAT- CONANP 2009).
} 
Guatemala, Belice y México. Su objetivo central es la coordinación internacional en materia de conservación de la biodiversidad y el uso sustentable de los recursos (SEMARNAT-CONANP, 2009). Otra forma de cooperación regional ha sido con Europa, a través del programa PRODESIS (2008). En materia de cooperación bilateral, México ha trabajado con Guatemala y Cuba para hermanar áreas protegidas. Finalmente, la cooperación con los EE.UU. (USAID) inició desde 1987 (CONANP-SEMARNAT, 2009).

\subsection{Los problemas}

La política ambiental mexicana cuenta con legislación, instituciones y programas para conservar la biodiversidad y detener algunos procesos de deterioro ambiental, sin embargo, para algunos ambientalistas, la conservación está perdiendo la batalla porque los gobiernos federales no fortalecen las acciones de conservación y porque el conservacionismo ha perdiendo el vigor, influencia y eficacia de antaño.

Las ANP siguen reportando problemas crónicos: falta de continuidad en programas, presupuesto insuficiente, falta de articulación intergubernamental, intereses privados, falta de aplicación de la ley, falta de planeación territorial (De la Maza y De la Maza, 2005), deficiencias en los decretos de las áreas y los planes de manejo $(\mathrm{CNDH}$, 2016; Azuela et al., 2008) ${ }^{9}$, además de problemas propios de la región en la que se ubican las áreas: distancias y dificultades de comunicaciones, nivel conciencia, organización y movilización de habitantes, incluyendo "la diversidad de actores con distintas concepciones del uso del territorio" y "los distintos usos de los pueblos indígenas" (Entrevista 81015-Conanp).

Un problema se refiere a la propiedad de la tierra en las que se ubican las ANP; la mayoría de las cuales fueron creadas en lugares donde ya existían asentamientos humanos (Bezaury-Creel et al., 2009). Las ANP federales generalmente se crean en propiedad social (ejidos y comunidades agrarias). Por ejemplo, las ANP ocupan 10,722,458 hectáreas de propiedad social (Bezaury-Creel et al., 2009, p. 391). Un problema importante ha sido que las ANP han sido creadas sin consultar previamente a los habitantes y dueños de los territorios donde fueron establecidas (De la Maza y De la Maza, 2005; SEMARNAP, 2000). La ley establece y requiere de esquemas y procesos de participación social, sin embargo, los reclamos por la falta de consulta inicial persisten. Otro problema ha sido la restricción al uso de los recursos naturales que la población que habita legalmente utilizaba hasta la creación de la ANP (Legorreta et al., 2014; Paré y Fuentes, 2007; ver Declaratoria del Encuentro sobre Reservas Campesinas y de la Biosfera ${ }^{10}$ ).

El decreto de creación de una ANP y su zonificación crean tipos de propiedad:

En muchos casos a estos decretos le siguen otro tipo de reglamentos -como los programas de manejo y ordenamientos ecológicos- con los cuales se busca normar y regular el acceso y uso que determinada

\footnotetext{
9 Por ejemplo, i) recategorización que no ha repercutido en la actualización de decretos, ii) lineamientos de manejo y vigilancia insuficientes, iii) falta de reglas de operación y de lineamientos para actividades dentro de ANP; iv) zonificación debe ser parte de decretos de creación de ANP pues se busca limitar el derecho de los individuos a realizar cualquier actividad dentro de ellas.

10 Veracruz, México 2004: >www.ecoportal.net/Eco-Noticias/Declaratoria_del_Encuentro_sobre_Reservas_Campesinas_y_de_la_Biosfera>.
} 
población hace de los recursos naturales y de esta forma garantizar su conservación. (Legorreta y Márques, 2014, p. 131).

Un problema tácito es la amenaza confiscatoria:

México es de los pocos países en el mundo donde los terrenos de las reservas y parques nacionales no pertenecen a la nación, sino que tiene dueños privados, ya sean ejidos, comunidades o pequeños propietarios. En la práctica, se ha visto que éste es un elemento que genera grandes obstáculos para el correcto manejo y protección de las ANP (Moctezuma, 2016).

Este tipo de posturas da sustento a reclamos de la apropiación de la naturaleza (Fairhead et al., 2012), reclamos de autoritarismo ambiental (Legorreta et al., 2014) y alienta la desconfianza de los dueños de las tierras hacia las autoridades ambientales.

Por otra parte, en términos de Derechos Humanos, el problema radica en la falta de un programa de manejo. Por ejemplo, hasta 2015, los programas de manejo de Lacan-Tún y Chan-Kín están pendientes de hacerse ${ }^{11}$. Sobre este punto, destaca el documento titulado Recomendación General número 26 sobre la falta y/o actualización de programas de manejo en áreas naturales protegidas de carácter federal y su relación con el goce y disfrute de diversos derechos humanos. Este documento fue publicado en abril de 2016 por la Comisión Nacional de los Derechos Humanos de México (CNDH); contiene quince recomendaciones del ombudsman mexicano dirigidas al Secretario de Medio Ambiente y Recursos Naturales (SEMARNAT) y al Comisionado Nacional de Áreas Naturales Protegidas (CONANP), poniendo énfasis en inexistencia, falta de actualización o inaplicación de instrumentos rectores para el manejo, administración y zonificación de las áreas protegidas, lo que deriva en afectaciones a derechos humanos $(\mathrm{CNDH}$, 2016; 2016a). La Recomendación General número 26 tiene tres objetivos: resaltar la perspectiva de Derechos Humanos sobre las áreas protegidas, en oposición a esquemas netamente ambientalistas, observar el marco legal vigente en materia ambiental y la adopción de las mejores prácticas en la materia ambiental. La CNDH concluye que los ecosistemas, en algunas ANP, se han deteriorado y lo que podría llevar a la pérdida del estatuto de protección.

Otros problemas crónicos incluyen la falta de continuidad en programas, presupuesto insuficiente, falta de articulación intergubernamental, intereses privados, falta de aplicación de la ley, falta de planeación territorial (De la Maza y De la Maza, 2005), deficiencias en los decretos de las áreas y los planes de manejo, incluyendo la diversidad de actores con distintas concepciones del uso del territorio y los distintos usos de los pueblos indígenas $(\mathrm{CNDH}$, 2016; Azuela et al., 2008. ${ }^{12}$

\section{Cartografía y análisis de uso de suelo}

De acuerdo con la LGEEPA, las Áreas Naturales Protegidas (ANP) son las zonas del territorio

\footnotetext{
11 Tienen planes de manejo: Montes Azules (2000), Najá y Metzabok (2009), así como Bonampak y Yaxchilán (2010), <www.conanp.gob. $\mathrm{mx} / \mathrm{que}$ hacemos/programa_manejo.php>.

12 Por ejemplo, i) recategorización que no ha repercutido en la actualización de decretos, ii) lineamientos de manejo y vigilancia insuficientes, iii) falta de reglas de operación y de lineamientos para actividades dentro de ANP; iv) zonificación debe ser parte de decretos de creación de ANP pues se busca limitar el derecho de los individuos a realizar cualquier actividad dentro de ellas.
} 


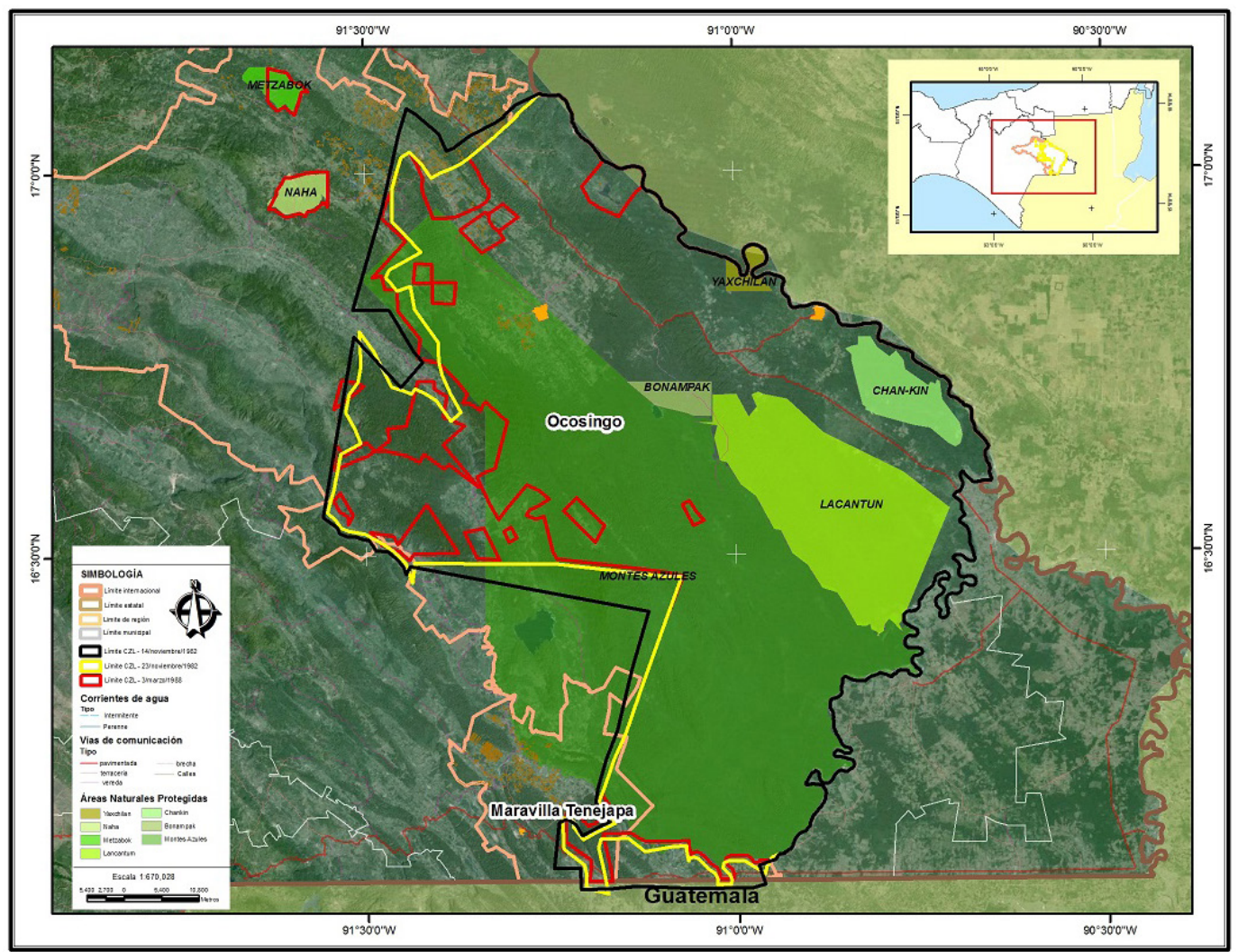

FIGURA 1 - El territorio de la Comunidad Zona Lacandona. Nota: el perímetro en negro se refiere a la primera demarcación que se realizó del polígono de la CZL (14 de noviembre de 1982); el perímetro en amarillo se refiere al segundo intento de demarcación del polígono (23 de noviembre de 1982). El perímetro en rojo marca el tercer intento por deslindar el polígono referido (3 de marzo de 1988).

FUENTE: Elaboración con base en: 1 Marco Geoestadístico, 2013 de INEGI; 2 ANP, 2015 de CONANP; 3 Secretaría de la Reforma Agraria. Programa de Atención Integral a la Comunidad Zona Lacandona y la Reserva de la Biosfera Montes Azules. Principales Resultados. Abril 2007. México. [Presentación obtenida mediante solicitud de acceso a información pública].

TABLA 2 - Áreas Naturales Protegidas en la CZL.

\begin{tabular}{lclccc}
\hline \multicolumn{1}{c}{ Nombre } & $\begin{array}{c}\text { Fecha de } \\
\text { creación }\end{array}$ & \multicolumn{1}{c}{ Categoría } & $\begin{array}{c}\text { Extensión } \\
\text { Has }\end{array}$ & $\begin{array}{c}\text { Plan de } \\
\text { manejo }\end{array}$ & $\begin{array}{c}\text { Superficie de } \\
\text { CZL }\end{array}$ \\
\hline Montes Azules & 1978 & Reserva de Biosfera & 331,200 & $\mathrm{Si}$ & 262,000 \\
Lacan-Tún & 1992 & Reserva de Biosfera & $61,873-96-02.5$ & No & 61,873 \\
Chan-Kin & 1992 & Área de Protección de Flora y Fauna & $12,184-98-75$ & 12,184 \\
Yaxchilán & 1992 & Monumento Natural & $2,621-25-23$ & $\mathrm{Si}$ & 2,621 \\
Bonampak & 1992 & Monumento Natural & $4,357-40-00$ & $\mathrm{Si}$ & 4,357 \\
Najá & 1998 & Área de Protección de Flora y Fauna & 3,847 & $\mathrm{Si}$ & 3,847 \\
Metzabok & 1998 & Área de Protección de Flora y Fauna & 3,368 & $\mathrm{Si}$ & 3,368 \\
Área total & & & & $\mathbf{3 5 0 , 2 5 0}$ \\
\hline
\end{tabular}

FUENTE: elaboración propia con datos de <www.conanp.gob.mx/que_hacemos/reservas_biosfera.php>. Consultado: 11 de febrero de 2015. 


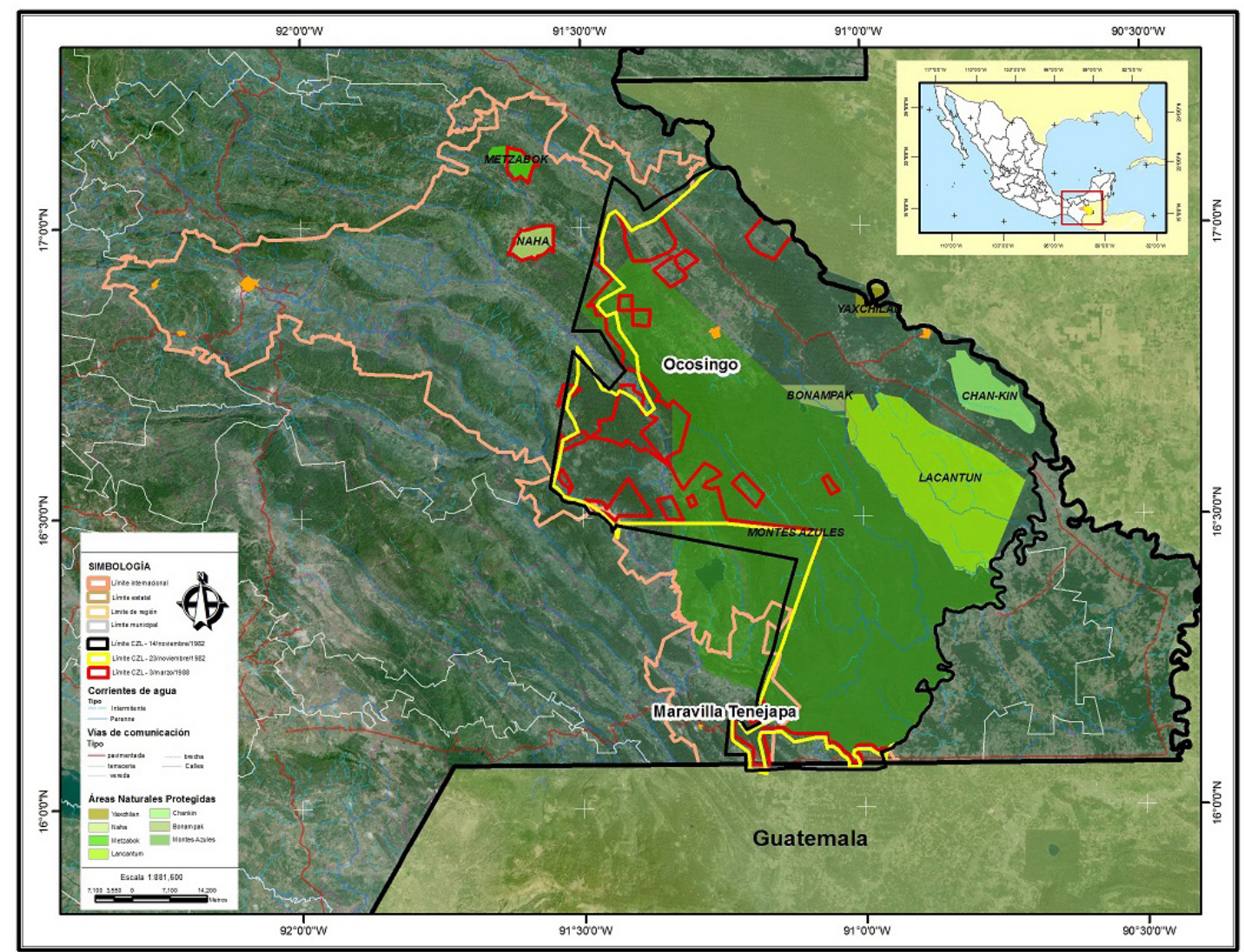

FIGURA 2 - Ubicación de las ANP.

FUENTE: Elaboración con base en: 1 Marco Geoestadístico, 2013 de INEGI; 2 ANP, 2015 de CONANP.

nacional sobre las que la nación ejerce su soberanía y jurisdicción para salvaguardar los ambientes originales de alto valor natural que no han sido significativamente alterados por la actividad del ser humano y que, por lo tanto, son áreas que requieren ser conservadas, restauradas o preservadas (Garcés y Ruíz, 2010). Estas áreas son grandes espacios donde residen diversos asentamientos humanos, que tienen diferentes formas de relación con el medio ambiente. Por ejemplo, el análisis del cambio de uso de suelo es considerado como uno de los indicadores que describen tendencias, inercias y procesos en un territorio específico. Este apartado pretende identificar cómo ha sido la apropiación de estos espacios particularmente en algunas localidades de la CZL, durante el periodo 1990-2013. Según Bocco et al. (2001), analizar el proceso de cambio de uso y cobertura del terreno implica tres pasos principales: a) detección e interpretación cartográfica y digital del cambio, b) análisis de los patrones de cambio de cobertura y uso del suelo, y c) análisis de las causas del cambio de uso del suelo. Aunado a lo anterior, se analizan las características demográficas y geográficas de las ANP en la CZL en dos vertientes: a) cómo ha sido el crecimiento poblacional entre 1990 y 2015 y, b) cómo se han 
dado los cambios de uso de suelo entre 1990 y 2013. Después, se muestra el proceso de apropiación de las ANP por los habitantes de la región.

\subsection{El crecimiento poblacional}

La vida de cada individuo se da en un espacio específico, bajo un entorno natural con el que va interactuando a través de su vida, por lo que la forma de apropiación y uso de su entorno tiene ciertas características específicas que responden a un sistema de valores, creencias y prácticas compartidas que se ejecutan en un espacio (Guevara Romero, 2015). Es por ello, que resulta necesario conocer cuál ha sido el crecimiento poblacional de la zona de estudio, que características poseen los diferentes grupos que habitan y cómo ha sido la apropiación que han hecho de su espacio y entorno natural. El crecimiento poblacional es uno de los indicadores que nos muestra cómo va aumentando la población en un determinado periodo, es por ello que a continuación se muestran datos estadísticos de población, que nos permiten conocer la situación poblacional en la zona de estudio y posteriormente se mostrará cómo ha sido la apropiación de estos grupos que habitan la CZL.

En la Tabla 1, se muestran las localidades de la zona de estudio; como puede verse, la población

TABLA 1 - Población total de la CZL y su contexto estatal.

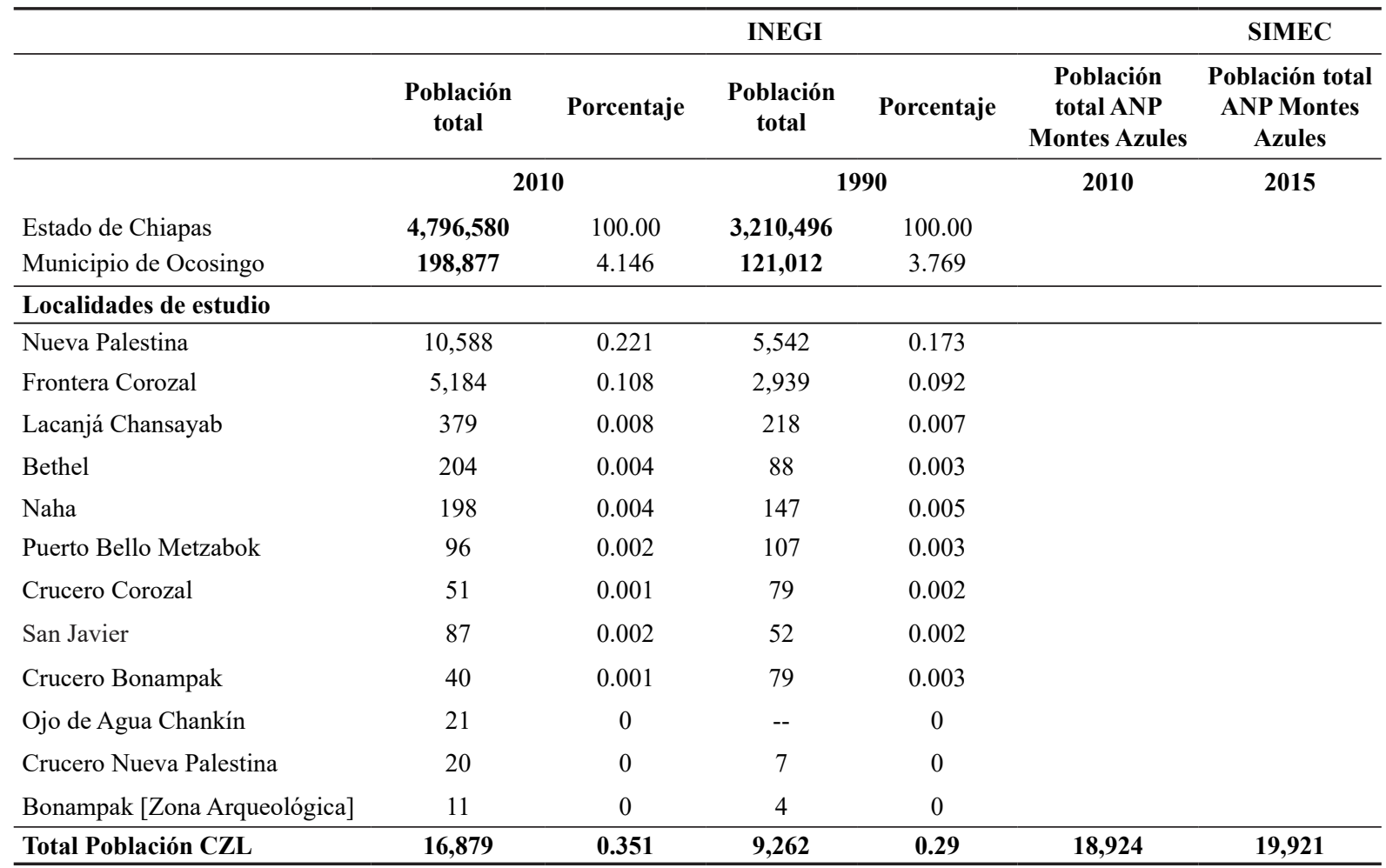

FUENTE: Elaboración con base en: 1 INEGI. Censo de Población y Vivienda, 2010; 2 INEGI. Censo de Población y Vivienda, 1990; 3 SIMEC. Ficha descriptiva por región de ANP, 2015. 
total del municipio de Ocosingo de acuerdo con INEGI (2010), representa el $4.15 \%$ de la población estatal y el $0.35 \%$ la población de las localidades que pertenecen a la CZL. Mientras que en 1990 se tenía una población del $0.28 \%$ incrementándose en un $0.07 \%$, por otro lado, según datos del SIMEC (2015) se tiene en el ANP Montes Azules una población total de 19,921 habitantes que representa el $0.41 \%$, como se muestra los datos son similares en la ANP Montes Azules, ya que, de acuerdo con el Censo de Población del 2010, se tenía 18,837 habitantes y de acuerdo a SIMEC del 2015, registra a una población de 19,921 habitantes. Lo anterior muestra que ha habido un crecimiento poblacional principalmente en localidades como Nueva Palestina y Frontera Corozal con casi un 50\% de incremento poblacional; en el caso de Nueva Palestina su crecimiento se ha dado en la ANP Montes Azules. Es importante mencionar que todo crecimiento poblacional implica el desarrollo de diversas actividades y que durante el proceso de crecimiento de la población se transformará el entorno ambiental.

Un punto relevante de mencionar, se refiere a los tamaños poblacionales de los grupos que conforman la CZL. Esta comunidad es interesante porque sus integrantes tienen diferentes prácticas. Por ejemplo, las estrategias de manejo de recursos naturales de los Lacandones tienen un impacto mínimo sobre los ecosistemas (Contreras Cortés et al., 2015; Diemont y Martin, 2009); los Lacandones pueden vivir en una relación poco intensa de recursos naturales; su tamaño poblacional es bajo y sus estándares ecológicos parecen ser incompatibles con una población creciente en la selva (Contreras Cortés et al., 2015; Diechtl, 1988). Aunque también hay procesos de cambio en el uso de los recursos naturales, como la urbanización, el consumo y, sobre todo, la sedentarización -alentada, entre otras cosas, por el proceso de colonización y reparto agrario. En su operación, la política de conservación ambiental ha aprovechado las prácticas de las poblaciones locales. Pero la selva también es una región de otros grupos. Por ejemplo, la población de Nueva Palestina (hablantes de la lengua Tseltal) y Frontera Corozal (lengua Chol) realizan actividades predominantemente agrícolas y ganaderas, y son actividades que parecen absorber a la población joven (Legorreta et al., 2014). En la Selva Lacandona hay aproximadamente, 73 localidades rurales y 2 localidades urbanas, cuya población suma 18,837 habitantes, se encuentran distribuidas principalmente en la parte norte de la CZL: trece localidades se encuentran dentro de la RBMA y su población suma 3,065 habitantes (Figura 3). También es importante mencionar que existen diversos indicadores sociales que nos muestran la situación de una comunidad como son el grado de marginación, el rezago social, índice de desarrollo urbano, entre otros. En este caso, los indicadores que tienen son a nivel municipal y se presentan de la siguiente forma: De acuerdo a los Indicadores de medición de la pobreza y la Medición de la Pobreza de CONEVAL (2010a y 2010b), el municipio se encuentra en un grado de marginación muy alto, situación que refleja que hay carencias en acceso a la educación, la residencia en viviendas inadecuadas y la carencia de bienes, elementos esenciales para el desarrollo de sus capacidades básicas. Otro de los indicadores es el grado en rezago social, que se presenta en las comunidades de la CZL con un nivel alto, según el Índice de Rezago Social de CONEVAL (2010); a pesar de que existe acceso a la educación y a servicios básicos, el grado que se presenta muestra que estos servicios son insuficientes. Esto se relaciona con la dispersión espacial que existe en la zona de estudio, ya que la dotación de servicios básicos llega principalmente a las zonas urbanas alejadas de estas localidades principalmente rurales. Cada 
uno de estos indicadores reflejan las carestías que existen en la CZL, sin embargo, inmersos en una zona con riqueza natural, es imposible no hacer uso de sus recursos naturales ya que también representa un recurso económico para su subsistencia y como lo menciona PRODESIS (2008) en el Libro Blanco de la Selva Lacandona: "Las actividades de extracción forestal han sido las predominantes en la historia económica de la región. La explotación de maderas preciosas, practicada comercialmente desde hace más de un siglo, antes del proceso de poblamiento y colonización, se concentraron en el corte y aserrío de caoba y cedro; además, se ha realizado la extracción de chicle, hule y de barbasco y, actualmente, tiene importancia la recolecta de hojas de palma camedor -xate- y pita". Derivado de lo anterior y aunado a los indicadores mostrados, el cambio de uso y uso de suelo, parece ser el punto de persistente tensión entre las autoridades ambientales y la CZL.

$\mathrm{El}$ crecimiento poblacional contribuye a entender la expansión en el uso de los recursos naturales (Entrevista 81015-Conanp):

La relación que se establece que dice: esta gente esta pobre porque tiene restricciones en el uso de sus recursos, es falso. Tú ves los sitios donde no hay

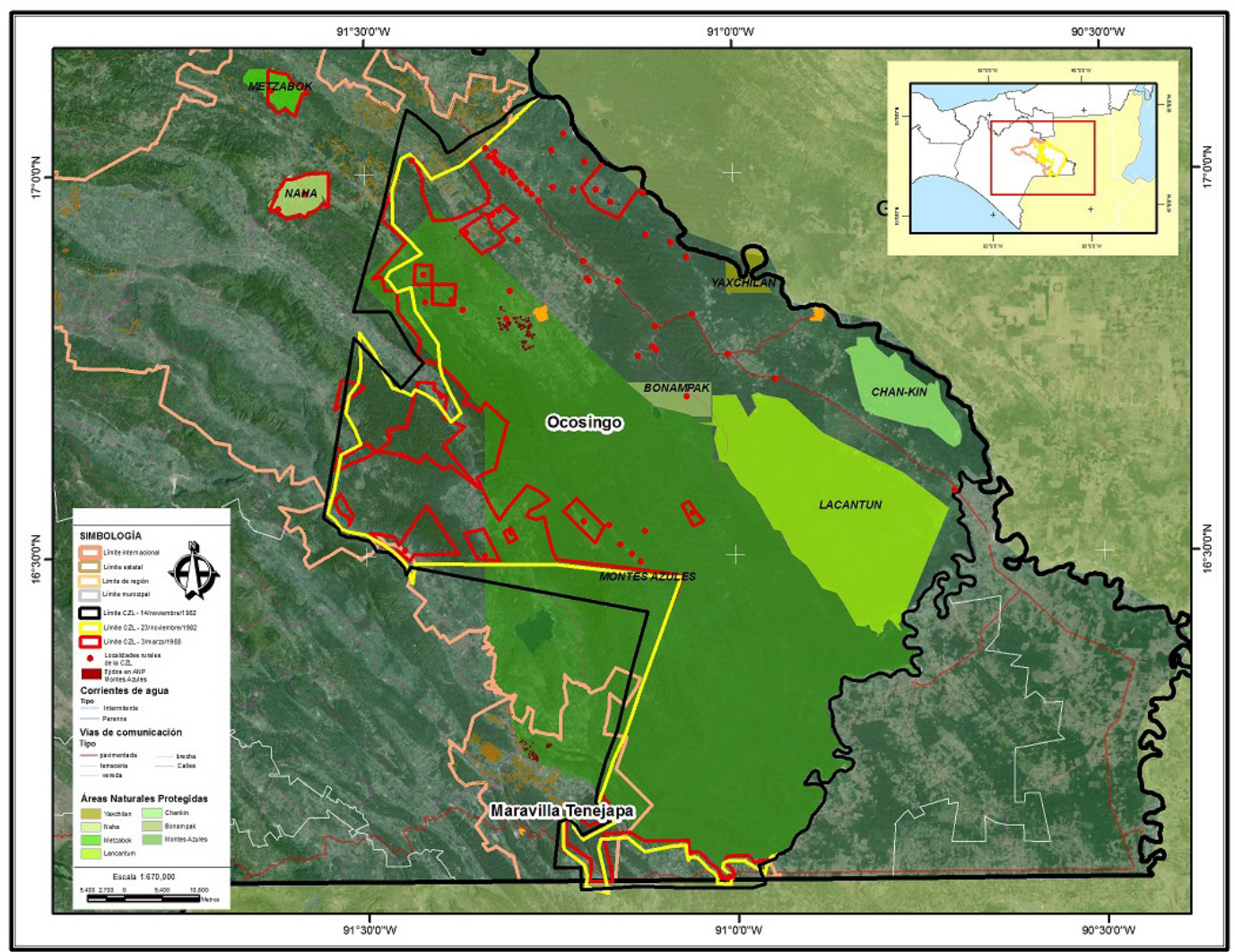

FIGURA 3 - Localidades rurales en la Comunidad Zona Lacandona.

FUENTE: Elaboración con base en: 1 Marco Geoestadístico, 2013 de INEGI; 2 Límite de Comunidad Lacandona; 3 ANP, 2015 de CONANP; 4 Limite ejidal del Registro Agrario Nacional. 
restricciones; incluso donde las pocas restricciones legales que hay, son obviadas, como en los altos de Chiapas y la situación de pobreza es mucho más marcada que en la selva. No es esa la relación.

Como en el resto del sistema agrario mexicano (ejidos y comunidades agrarias), el crecimiento población ha generado cambios de varios tipos, incluidos los roles de género. Por ejemplo, las mujeres jóvenes (hijas de los comuneros) aunque no tienen derecho de voz, voto ni asistencia a las asambleas comunales, sí tienen derecho de voto en las elecciones constitucionales municipales, estatales y federales; aunque está pendiente la investigación de la pluralidad electoral de la Selva Lacandona y de la CZL, la participación de las mujeres, sobre todo de las jóvenes, han contribuido a la pluralización política (Entrevistas 24plm; 512s). De cualquier manera, persisten, procesos de exclusión dentro de la CZL, y los jóvenes, en general, demandan recreación y empleo (Entrevista $25 \mathrm{sl}$ ), incluso representación (Entrevista 115er) y tierra:

La mayoría de jóvenes entre 18 y 20 años, demandan tierra. En la actualidad, en la CZL ya no hay tierra para distribuir a los jóvenes (Entrevista 37ccc).

\subsection{El cambio de uso de suelo}

Los cambios de uso de suelo en la CZL suceden a pesar de las restricciones sobre el uso de recursos. Es a través de los cambios en el uso del suelo que se plasma la relación medio ambiente y sociedad, por la forma en que hacen uso de su entorno. En la Selva Lacandona, en las últimas décadas, ha habido una fuerte transformación de los ecosistemas de esos territorios. Las rápidas y profundas transformaciones del uso del suelo, así como las consecuencias que generan, son temas de interés actual en las disciplinas ambientales; los cambios de uso de suelo ocurren a nivel local, pero la pérdida de la biodiversidad y la extinción de especies pueden tener consecuencias globales. El uso del suelo está estrechamente conectado a la sustentabilidad de los recursos naturales, por lo tanto, la persistencia de los ecosistemas está determinada por la intensidad con que se modifica la capa vegetal, por eso es importante conocer los procesos de cambio de uso del suelo y sus efectos.

En este trabajo se trata de mostrar como el crecimiento poblacional, los indicadores sociales y las actividades de las localidades de la CZL ha tenido su apropiación en las ANP.

En las Tablas 3 y 4 se muestra las superficies de cada tipo uso de suelo y vegetación. Como puede verse los mayores cambios se encuentran principalmente en la selva alta: entre 1990 y 2013, hubo un decremento de 57,365 hectáreas y el mayor incremento se dio en los pastizales, la agricultura de temporal y hubo un alto incremento de la vegetación secundaria en las selvas altas con 10,998, 7,928 y 30,746 hectáreas, respectivamente; “en la mayoría de los casos la tendencia generalizada en la dinámica del cambio de uso del suelo, es hacia el establecimiento de pastizales, derivado del pastoreo extensivo de ganado bovino, lo cual resulta en un proceso prácticamente irreversible en términos ambientales y de pérdida de biodiversidad" (PRODESIS, 2008).

Con respecto a las zonas urbanas, el crecimiento ha sido lento pero continuo, mientras que han ido apareciendo asentamientos humanos mostrando un crecimiento de 132 hectáreas, como es el caso de las localidades de Nueva Palestina y Frontera Corozal, donde se tuvo un crecimiento aproximado del $50 \%$, en un periodo de 15 años. Los principales cambios en el uso de suelo y vegetación en los periodos 1990 y 2013 , como puede verse de 
forma espacial en la Figura 4, se encuentran en la RBMA. Es evidente que los procesos de deforestación y degradación de recursos naturales en la Selva Lacandona presentan el mayor dinamismo fuera de las áreas naturales protegidas, esto como ya se ha mencionado es derivado de las actividades de extracción forestal, que han sido predominantes en la economía de la CZL. Al interior de éstas, los procesos más dinámicos y de mayor impacto se desarrollan en los asentamientos o núcleos agrarios regulares, dueños de la tierra que ocupan.

Con respecto a las superficies de cada tipo de uso de suelo y vegetación en las ANP de la comunidad, como se mencionó anteriormente, la RBMA es la que abarca la mayor superficie de ésta $(331,200$ hectáreas); la reserva presenta grandes cambios: incremento de la agricultura de temporal, una gran expansión de la frontera agrícola hacia la selva alta con 7,928 hectáreas y decrementos de la selva alta perennifolia con 57,365 hectáreas que transitaron hacia vegetación secundaría arbórea y arbustiva con 30,746 hectáreas. Estos cambios son el reflejo de como la agricultura es la base de la reproducción social en CZL, constituida por un estándar agrícola con cultivos predominantes como son el maíz, frijol, café y chile, también de la producción pecuaria donde predomina la ganadería bovina en pastoreo extensivo (mostrando un incremento de pastizales de 9,343 a 20,331 hectáreas) y aunado a lo anterior, la tala clandestina, la explotación no planificada de recursos naturales, los incendios forestales, entre otros, han contribuido a los principales cambios encontrados en la región de estudio.

En cuanto al uso de suelo en las localidades de la CZL, los ejidos que la circundan no han estado exentos del uso de los recursos de su entorno. La Figura 4 muestra las zonas en donde principalmente crecieron los asentamientos humanos y muestra cierta perturbación de la vegetación origen -como es el caso de las zonas donde había selva alta perennifolia y en la actualidad se puede ver que se encuentra perturbada y presentan grandes zonas de vegetación secundaria. Esta figura también muestra que el crecimiento de asentamientos humanos, abarcó alrededor de 134 hectáreas. En particular, NP creció casi al doble en las últimas dos décadas. Este asentamiento Tseltal creció demográficamente: de 5,542 a 10,588 habitantes. Además, en términos de superficie, NP creció sobre zonas de agricultura de temporal y de selva alta perennifolia (INEGI. Censos de Población y Vivienda, 1990 y 2010 y Carta de uso de suelo y vegetación, 2013).

En la Selva Lacandona, pareciera que el crecimiento poblacional y el cambio de suelo cuestionan la eficacia de las ANP como estrategia de conservación. En primer lugar, la población de la CZL tiene necesidades que tradicionalmente ha suplido con los recursos naturales de su entorno. La investigación etnográfica ha contribuido a comprender la forma en que poblaciones locales utilizan los recursos naturales de su entorno y las restricciones que la política ambiental ha establecido. En contra de las restricciones de uso sobre los propios dueños de las tierras, surgen grupos de la propia CZL que invaden zonas en conservación. Así mismo, las restricciones en la tenencia de la tierra plantean, a los comuneros, preguntas sobre la titularidad de los derechos sobre las tierras en las que se asientan las ANP (Entrevista CCY); este es un punto observado por varios autores: "aunque esas tierras legalmente les pertenecen, no pueden usarlas ni decidir sobre ellas" (Durand y Figueroa, 2014). Consecuentemente, las poblaciones locales cuando quieren usar y/o detentar propiedad sobre los recursos naturales de su entorno, entran en conflicto con regulaciones que ha creado el gobierno para la zona. Sin embargo, la operación de la política ambiental en la Selva, aunque restringe el uso 
y tenencia de la tierra y recursos naturales, requiere de la cooperación de los comuneros. Para Legorreta y Márquez (2014), las actuales formas de manejo agrícola, ganadero y extractivo que se realizan en la Selva Lacandona, junto con el crecimiento de la población, han provocado en los años últimos 50 años, un acelerado deterioro y agotamiento de los recursos naturales de la región, pérdida de gran riqueza económica y biológica.

Pero además del crecimiento poblacional, el cambio de uso y cobertura de terreno es el punto de persistente tensión entre las autoridades ambientales y la CZL; el cambio de uso y cobertura sucede a pesar de la existencia de restricciones sobre el uso de recursos se relaciona con la tenencia de la tierra, y el tema desarrollo-pobreza.

La línea de deforestación es la frontera del AP, precisamente en la zona de las Cañadas, en la zona norte-noroccidental de la reserva [Montes Azules], tu ve la línea de la reserva en el mapa y corresponde con la línea de cobertura arbórea. (Entrevista 81015-Conanp).

Un estudio de cambios de uso de suelo realizado en el libro blanco de "La Selva Lacandona" (PRODESIS, 2008) calcula que entre 1979 y 1993 se deforestaron 469,145 has de selva.

Los datos que presentamos indican que Metzabok perdió 48 hectáreas, sin embargo, es importante mencionar que se ha ido recuperando lentamente en algunas zonas cercanas:

Tú puedes ver, Najá y Metzabok son buenos ejemplos..., como está esa superficie y cómo está lo que está fuera de esas dos porciones de los Bienes Comunales $[C Z L]$... [...] esas dos zonas de protección están perfectamente delimitadas, con brecheo que se realiza cada año. Si donde tienes eso [la ANP], tienes el ecosistema en buen estado y donde no lo tienes [la ANP] y a no tienes el ecosistema con los servicios que ello provee, parece evidente que funciona. (Entrevista 81015-Conanp).

Un escenario menos positivo lo presentan Chan-Kin y Lacan-Tún.

\begin{abstract}
La tasa de deforestación dentro de un área protegida, aunque no se evita completamente, es mucho menor que la que hay fuera... ahorita estamos definiendo una forma de monitoreo [...] que permite detectar en tiempo real si se está viendo alguna modificación y nos está permitiendo tener claro eso. Las AP, hasta el momento, no solo funcionan; son las únicas herramientas que han funcionado en México para mantener la biodiversidad (Entrevista 81015-Conanp)
\end{abstract}

La tensión comuneros- autoridades ambientales exige eficacia del gobierno. Por ejemplo, para los comuneros de la CZL, una forma de cuidar la Selva es evitar invasiones de tierra; por ello, presionan al gobierno para que desaloje a grupos invasores de sus tierras. La peor situación para los comuneros es verse impedidos de utilizar las tierras que legalmente les pertenecen, pero ver que grupos invasores lo hagan (Durand y Figueroa, 2014).

En suma, la conservación del medio ambiente es una relación de cooperación, las poblaciones locales cuando quieren usar y/o detentar propiedad sobre los recursos naturales de su entorno, entran en conflicto con regulaciones que ha creado el gobierno el para la zona. Es un conflicto en el que el gobierno y los comuneros intentan el controlar el uso de los recursos naturales de la selva. 
TABLA 3 - Uso de suelo y vegetación de 1990-2013.

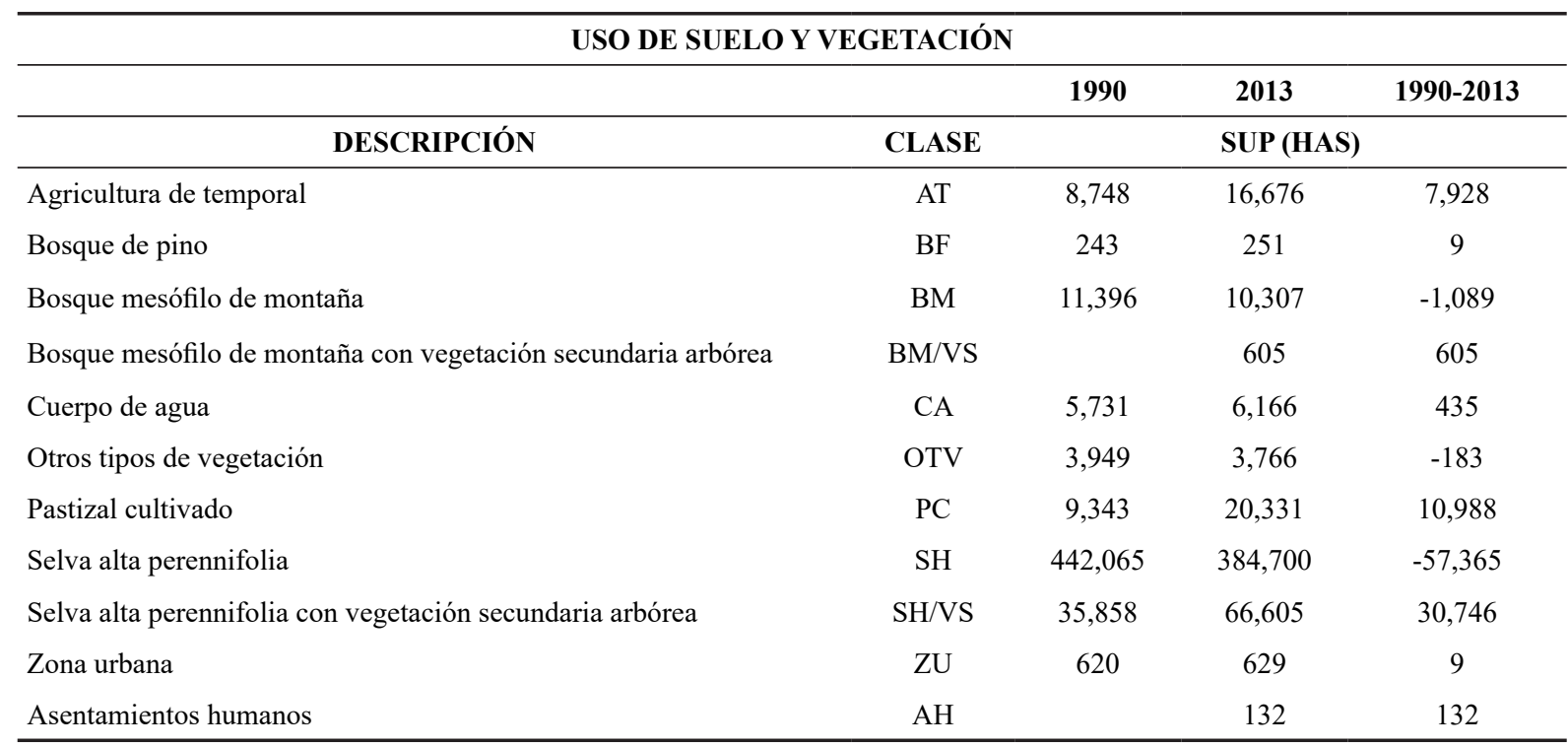

FUENTE: Elaboración con base en: 1 Marco Geoestadístico, 2013 de INEGI; 2 Carta de uso de suelo y vegetación, 1990 de INEGI; 3 Carta de uso de suelo y vegetación, 2013 de INEGI; 4 ANP, 2015 de CONANP; 5 Limite ejidal del Registro Agrario Nacional.

\subsection{Las alternativas económicas}

El crecimiento demográfico (se estima que entre 1990 y 2010, la población aumentó un 53\%) explica una parte del proceso de uso de los recursos naturales de la Selva. Si las restricciones en el uso de los recursos y el crecimiento poblacional generan presiones sobre los recursos naturales, entonces parece necesario que la actividad económica y las fuentes de ingreso para los moradores sean desarrolladas. Si el uso de recursos naturales continua y si la población crece, pareciera que la tensión autoridades ambientales - comuneros se centraría en la forma de uso o conservación de los mismos. Las actividades económicas de las etnias Tseltal, pero también Chol, incluyen a la ganadería, que es una actividad expansiva, que utiliza tierras que antes eran destinadas a la agricultura (Legorreta y
Márquez, 2014). El cultivo de maíz y frijol, principal fuente de alimento, se produce actualmente bajo el sistema de roza-tumba-quema, técnica que implica la deforestación de la cobertura vegetal en la parcela que se utilizará para la siembra. Sin embargo, la gran población que demanda frijol y maíz causa sobrexplotación, erosión de terrenos y pérdida de fertilidad del suelo por la reducción de los periodos de descanso (Legorreta y Márquez, 2014). También practican la extracción de recursos forestales no maderables como la palma camedor o xate, cuyas hojas se destinan principalmente a arreglos florales y que se recolecta durante todo el año en la Selva desde la década de los años 70 (Buda y Trench, 2007; Sánchez y Valtierra, 2003). Esta actividad económica, importante en la CZL, no se realiza de forma sustentable, pues las cantidades extraídas rebasan los límites adecuados para posibilitar su reproducción (Legorreta y Márquez, 2014). 
TABLA 4 - Tipos de uso de suelo y vegetación de 1990-2013 de las ANP en CZL.

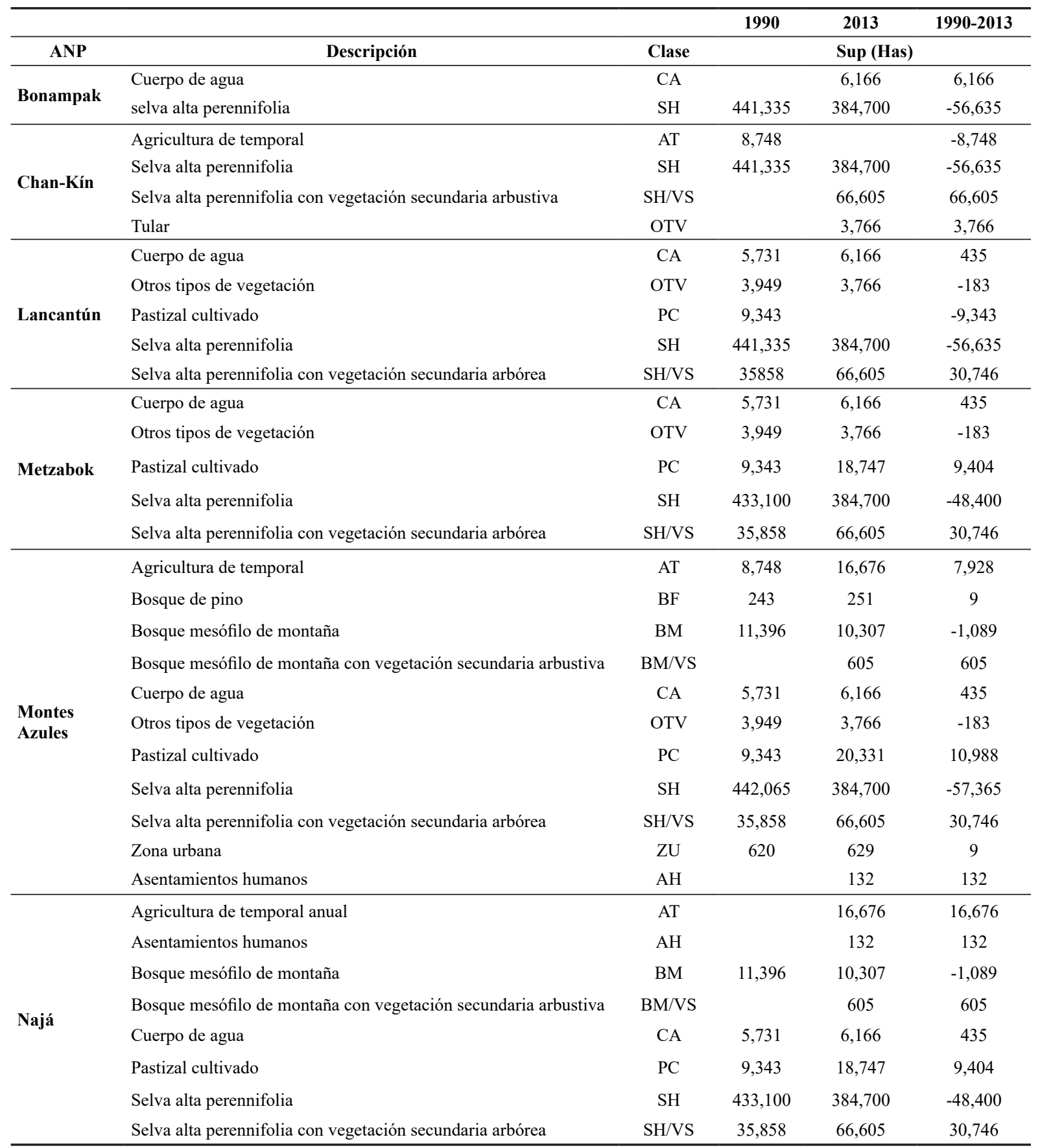

FUENTE: Elaboración con base en: 1 Marco Geoestadístico, 2013 de INEGI; 2 Carta de uso de suelo y vegetación, 1990 de INEGI; 3 Carta de uso de suelo y vegetación, 2013 de INEGI; 4 ANP, 2015 de CONANP; 5 Limite ejidal del Registro Agrario Nacional. 


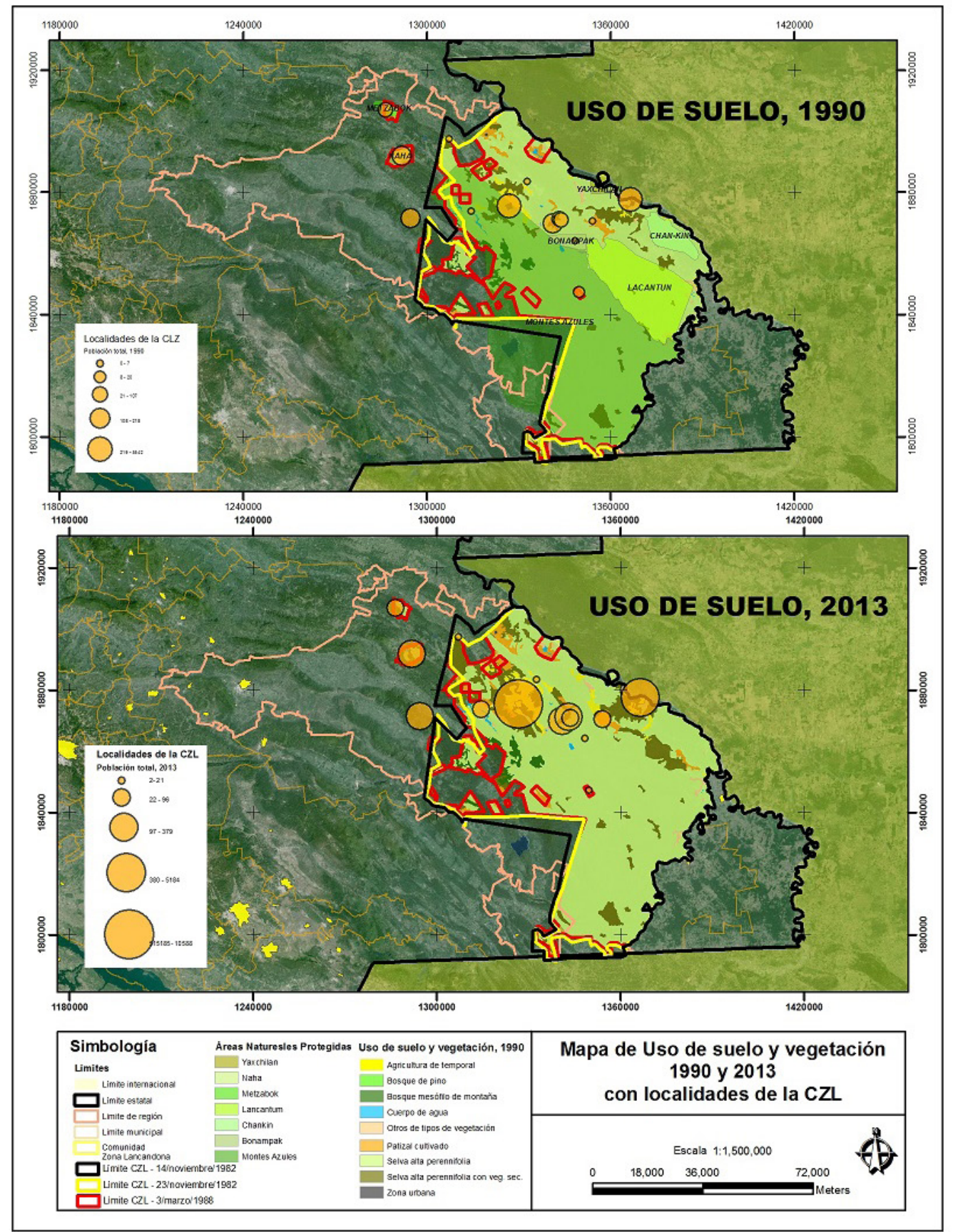

FIGURA 4 - Uso de suelo y vegetación de 1990-2013.

FUENTE: Elaboración con base en: 1 Marco Geoestadístico, 2013 de INEGI; 2 Límite de Comunidad Lacandona; 3 ANP, 2015 de CONANP. 
La actividad económica se ha diversificado. Por ejemplo, la ganadería, tiene el reto de que el terreno no es adecuado en Lacandonia; la forma en que se realiza lleva a la apertura de mayores áreas de pastoreo y con poca tecnificación, pero empleando a toda la familia (Entrevista 25sl). El turismo no es una actividad reciente. Para los Lacandones, desde 1945, con el hallazgo de Bonampak, se convirtieron, informalmente, en anfitriones y guías de turistas y en artesanos con turistas, exploradores que llegaban en aviones desde Tenosique, Palenque, San Cristóbal.

En términos de actividad económica, los lacandones han practicado la agricultura, la caza, la pesca, el tejido (ropa, hamacas, bolsas), la cestería, apicultura, el comercio (artesanías) y la recolección (Tozzer, 1962; Villa Rojas, 1967). Sin embargo, ha sido el desarrollo del ecoturismo el que ha generado tensiones, entre quienes tienen iniciativa, recursos y capacidad para organizarse, acceder a fondos y desarrollar una actividad: el transporte terrestre (taxis) y acuático, por el río Usumacinta a Yaxchilán, es un ejemplo. Para los comuneros (Entrevista 24plm) el ecoturismo se desarrolla gracias a quienes tienen capital original para montar una oferta de servicios; otros grupos que buscan constituirse después enfrentan resistencias y competencia establecida. Lanchas para transporte de trabajadores a parcelas y para turismo (Yaxchilán) -junto con hospedaje y alimentos (Entrevista 52cag). La conservación también ha generado trabajos asalariados: la contratación de personal para tareas de monitoreo es otro tema en tensión con autoridades ambientales porque los comuneros quieren que sus familiares realicen esas tareas asalariadas, más que gente de afuera: los programas de ANP han diversificado las opciones de empleo en la zona, por ejemplo, creando la función de guarda parques (Entrevista 25sl).
Pero el desarrollo económico es incompleto si los programas no contemplan los problemas que la comunidad considera importantes. La experiencia de la CZL con el ecoturismo sugerir que las oportunidades de desarrollo económico no son universales, sino que se reducen a un número de personas con capital para dedicarse a ellas (Legorreta y Márquez, 2014).

Es precisamente en las necesidades de la población y en sus actividades económicas que se identifican las presiones sobre los recursos naturales: "a pesar de que población lacandona, chol, tzeltal y tzotzil coexiste y son copropietarios de la misma CZL, ha habido poca trasmisión de conocimientos y apropiación de técnicas más adecuadas entre ellos" (Diemont y Martin, 2009; Legorreta y Márquez, 2014 cfr. Meli et al., 2015; Contreras et al., 2013), por el contrario, el desarrollo del consumo y la necesidad de ingresos monetarios han aumentado.

Algunas alternativas económicas pueden radicar en proceso de transformación de lo que ya genera actividad económica, e incluir a los hijos de los comuneros: la palma camedor, tecnificación e intensificación de la ganadería; si esos terrenos que ya están transformados, generar actividades para disminuir la presión de abrir nuevos territorios y recuperas ciertos servicios ambientales de esos territorios.

\section{Conclusiones}

La viabilidad de las ANP situadas dentro de la CZL parece estar en función de las necesidades de las poblaciones locales. El crecimiento poblacional y el uso que hacen de los recursos naturales sugiere que la viabilidad de las áreas es difícil. La cooperación de los grupos Lacandones de Lacanjá Chansayab, Najá y Metzabok, pero sobre todo de la 
población de las dos localidades, Nueva Palestina y Frontera Corozal, para radicar en las alternativas de desarrollo extra-ambiental: economía y empleo, educación.

El interlocutor de la política ambiental mexicana, en la Selva Lacandona, es una población creciente, con problemas de pobreza y subdesarrollo económico; la conservación de la biodiversidad no sucederá si no se generan soluciones para esa población, aunque las soluciones sobre pasan la tarea de las autoridades ambientales. El reto más grande para el ambientalismo mexicano parece radicar en reconocer que las poblaciones indígenas son las dueñas de los territorios que habitan y que esa relación está protegida por marcos legales nacionales e internacionales y que esa relación es considerada como un Derecho Humano.

El acento sobre los Derechos Humanos lo puso la muy reciente Recomendación General 26 de la Comisión Nacional de los Derechos Humanos, resaltando la carencia de planes de manejo de muchas

\section{Referencias}

Azuela, A.; Cancino, M. A.; Contreras, C.; Rabasa, A. Una década de transformaciones en el régimen jurídico del uso de la biodiversidad. En: Conabio. Capital natural de México, v. III: Políticas públicas y perspectivas de sustentabilidad. México: Conabio, 2008. p. 259-282.

Bezaury-Creel, J.; Gutiérrez Carbonell, D. Áreas naturales protegidas y desarrollo social en México. En: Conabio. Capital natural de México, v. II: Estado de conservación y tendencias de cambio. México: Conabio, 2009. p. 385-431.

Brenner, L. Aceptación de políticas de conservación ambiental: el caso de la Reserva de la Biosfera Mariposa Monarca. Economía, Sociedad y Territorio, 30(9), 259295, 2009.

Bocco, G.; Mendoza, M.; Masera, O. La dinámica del cambio de uso del suelo en Michoacán. Una propuesta me-
ANP; estos planes son importantes porque establecen las reglas de colaboración entre autoridades ambientales y poblaciones locales para cumplir con los objetivos de conservación y sustentabilidad que tienen las áreas. A falta de una relación cooperativa, la alternativa es ejercer autoridad. Un gobierno autoritario es uno que caree de una relación dialogada, negociada; el diálogo autoridades ambientales y población local son los medios más seguros para lograr una política ambientalmente sustentable y socialmente viable. La falta de cooperación parece sugerir la última investigación sobre la CZL (Legorreta et al., 2014); al final, los recursos naturales son consumidos pero las poblaciones locales que habitan las reservas, no superan la pobreza. A pesar de la creciente investigación sobre la Selva Lacandona y la CZL, aún hace falta comprender mejor algunos el financiamiento de las ANP, el rol de gobiernos y organizaciones internacionales en esfuerzos de conservación, así como la triple relación Cambio Climático, CZL y ANP. todológica para el estudio de los procesos de deforestación. Investigaciones Geográficas, 44, 18-38, 2001.

Bollo, M. H.; José y Méndez, A. Áreas de Atención Prioritaria en México: una óptica medioambiental. Journal of Latin American Geography, 12(2), 61-82, 2013.

Buda, G.; Trench, T. Plan estratégico para el manejo sustentable de palma camedor (Chamaedorea spp.) en la Selva Lacandona. Informe Técnico. San Cristóbal de Las Casas, Chiapas, Universidad Autónoma Chapingo-SEMARNAT, 2007.

Calleros-Rodriguez, H. Land, Conflict, and Political Process: The case of the Lacandon Community (1972-2012). Journal of Peasant Studies, 41(1), 127-155, 2014. doi: 10.1080/03066150.2013.873891 
Carmona, C. Ley General del Equilibrio Ecológico y la Protección al Ambiente. México: IIJ-UNAM. Serie Doctrina Jurídica 125, 2003. Disponible en: $<$ http://biblio.juridicas. unam.mx/libros/2/542/1.pdf>.

Chiapas. Programa de Ordenamiento Ecológico del Territorio del Estado de Chiapas Modelo de ordenamiento ecológico del territorio. Memoria técnica - Modelo. Gobierno de Chiapas, 2012.

CNDH - Comisión Nacional de los Derechos Humanos. Recomendación General número 26 sobre la falta y/o actualización de programas de manejo en áreas naturales protegidas de carácter federal y su relación con el goce y disfrute de diversos derechos humanos. DOF 24 de abril de 2016.

CNDH - Comisión Nacional de los Derechos Humanos. 2016a. CNDH-Conferencia de prensa de la Recomendación General 26/2016 sobre Áreas Naturales Protegidas. Fecha del evento: 26 de abril de 2016. <https://www.youtube.com/ watch?v=aghgvJ9SmZU>.

CONANP - Comisión Nacional de Áreas Naturales Protegidas. Áreas Protegidas Decretadas. Disponible en: $<$ http:// www.conanp.gob.mx/que_hacemos/>. México: CONANP, 2016.

CONANP - Comisión Nacional de Áreas Naturales Protegidas; Secretaría del Medio Ambiente y Recursos Naturales (SEMARNAT). Mexico International Cooperation and Its Benefits for Conservation. México: CONANP-SEMARNAT, 2009.

CONEVAL. Índice de Rezago Social. 2010.

CONEVAL, Indicadores de pobreza seleccionados en el Estado de Chiapas. México, 2010a.

CONEVAL. Medición de la pobreza. 2010b.

Contreras Cortés, L.; Mariaca Méndez, R.; Pérez Farrera, M. El proceso de sucesión ecológica entre los Lacandones de Nahá, Chiapas, México. Etnobiología, 13(2), 49-62, 2015.

Costedoat, S.; Corbera, E.; Castillo-Santiago, M. How Effective Are Biodiversity Conservation Payments in Mexico? Plos ONE, Marzo 25. 2015. Disponible en: doi: 10.1371/ journal.pone.0119881

De la Maza, R. G.; De la Maza, J. Historia de las áreas naturales protegidas en México. Programa agua, medio am- biente y sociedad. Documento de trabajo núm. 5. México: El Colegio de México - UNAM, 2005.

Diario Oficial de la Federación (DOF). México, 7 de septiembre de 2012.

Diechtl, S. Cae una estrella, desarrollo y destrucción de la Selva Lacandona. México: SEP, 1988.

Diemont, S.; Martin, J. Lacandon Maya Ecosystem Management: Sustainable Design for Subsistence and Environmental Restoration. Ecological Applications, 19(1), 254-266, 2009.

Durand, L.; Figueroa, F.; Trench, T. Inclusión y exclusión en las estrategias de participación social en la Reserva de la Biosfera Montes Azules, Chiapas, México. En: Durand, L.; Figueroa, F.; Guzmán, M. (Eds.). La naturaleza en contexto: hacia una ecología política mexicana. México: UNAM y COLSAN, 2012. p. 237-268.

Entrevista 81015-Conanp, 2015.

Entrevista CCY. 27 de mayo de 2008. Comunidad Zona Lacandona.

Entrevista 24plm. 19 de junio de 2008. Comunidad Zona Lacandona.

Entrevista 25sl. 27 de junio de 2008. Comunidad Zona Lacandona.

Entrevista 37ccc. 12 de enero de 2010. Comunidad Zona Lacandona.

Entrevista 52cag. 13 de junio de 2008. Comunidad Zona Lacandona.

Entrevista 115er. 19 de mayo de 2008. Comunidad Zona Lacandona.

Entrevista 512s. 15 de junio de 2008. Comunidad Zona Lacandona.

Fairhead, J.; Leach, M.; Scoones, I. Green Grabbing: A new appropriation of nature? The Journal of Peasant Studies, 39(2), 237-261, 2012. doi: 10.1080/03066150.2012.671770

Figueroa, F.; Sánchez-Cordero, V. Effectiveness of natural protected areas to prevent land use and land cover change in Mexico. Biodiversity Conservation, 17, 3223-3240, 2012.

Garcés, C.; Ruiz, L. Características sociodemográficas de las áreas naturales protegidas de competencia federal en 
México. En: La situación demográfica de México 2010. México: CONAPO, 2010. p. 201-236, 2.

Guevara Romero, L. Estudio Territorial. Sierra Norte de Puebla. Ed. BUAP, 2015.

INEGI. Carta de Uso del Suelo y Vegetación, 1993 (Esc. 1:250 000) INEGI. México.

INEGI. Marco geoestadístico del Estado de Puebla, 2010 (Esc. 1:250 000)

INEGI. Carta de Uso del Suelo y Vegetación, 2013 (Esc. 1:250 000) INEGI. México.

Lagunas-Vázquez, M.; Beltrán-Morales, L.; Urciaga-García, J.; Ortega-Rubio, A. Evaluación rural participativa: uso de los recursos naturales en la reserva de la biosfera El Vizcaíno, BCS, México. Economía, Sociedad y Territorio, 26(8), 451-476, 2008.

Lee, A. Territorialisation, Conservation, and Neoliberalism in the Tehuacán-Cuicatlán Biosphere Reserve, Mexico. Conservation and Society, 12(2), 147-161, 2014.

Legorreta Díaz, C.; Márquez Rosano, C.; Trench, T. (Coords.). Paradojas de las tierras protegidas en Chiapas. México: UNAM (CEIICH-CRIM) - UACh, 2014.

Legorreta, C.; Márquez, C. ¿Es posible la conservación de las áreas protegidas por decreto? Retos sociopolíticos para la gestión ambiental democrática en las comunidades Nueva Palestina y Frontera Corozal, Ocosingo, Chiapas. En: Legorreta, C.; Márquez, C.; Trench, T. (Coords.). Paradojas de las tierras protegidas en Chiapas. México: UNAM (CEIICH-CRIM) - UACh, 2014. p. 129-171.

Meli, P.; Landa, R.; López-Medellín, X.; Carabias, J. Social Perceptions of Rainforest and Climatic Change from Rural Communities in Southern Mexico. Ecosystems, published online 18 de julio, 2015. Doi: 10.1007/s10021-015-9903-8

Merino, L.; Hernández, M. Destrucción de instituciones comunitarias y deterioro de los bosques en la Reserva de la Biosfera Mariposa Monarca, Michoacán, México. Revista Mexicana de Sociología, 66(2), 261-309, 2004.

México. Constitución Política de los Estados Unidos Mexicanos, 5 de febrero de 1917 [2015].

México. Ley General del Equilibrio Ecológico y la Protección al Ambiente. 1988.
México. Sistema de Información, Monitoreo y Evaluación para la Conservación (SIMEC), 2015. <https://simec. conanp.gob.mx/>.

Moctezuma, O. La conservación de la naturaleza en México, en peligro de extinción. La Jornada Ecológica, 205, 6-9, Abril-Mayo 2016.

Paré, L.; Fuentes, T. Gobernanza ambiental y politicas públicas en Áreas Naturales Protegidas. Lecciones desde Los Tuxtlas. México: UNAM- IIS, 2007.

Pinkus-Rendón, J.; Pinkus-Rendón, M. El ecoturismo: quimera o realidad de desarrollo en la Reserva de la Biosfera Ría Celestún, México. Revista LiminaR. Estudios Sociales y Humanísticos, 13(1), 69-80, 2015.

PO - Periódico Oficial. Programa de Ordenamiento Ecológico y Territorial del Estado de Chiapas. Órgano de difusión oficial del estado libre y soberano de Chiapas. Chiapas: Secretaría General de Gobierno, viernes, 7 de diciembre, 2012.

PRODESIS. Libro blanco de La Selva Lacandona. México: Unión Europea, Gobierno del Estado de Chiapas y EPYPSA, 2008.

Sánchez, D.; Valtierra, E. La organización social para el aprovechamiento de la palma camedor (Chamaedorea spp.) en la selva Lacandona, Chiapas. Agrociencia, 37(5), 545-552, sept.-oct. 2003.

SEMARNAP - Secretaría de Medio Ambiente, Recursos Naturales y Pesca. Balance del Programa Nacional de Áreas Naturales Protegidas 1995-2000. México: SEMARNAP, 2000.

SEMARNAT - Secretaría de Medio Ambiente y Recursos Naturales. Plan Nacional de Desarrollo. Programa Sectorial de Medio Ambiente y Recursos Naturales (Promarnat). México, 2013.

SEMARNAT - Secretaría de Medio Ambiente y Recursos Naturales. Programa Sectorial de Medio Ambiente y Recursos Naturales 2007- 2012. México: SEMARNAT, 2007.

Tozzer, A. M. Mayas y Lacandones, un estudio comparativo. México: INI, 1962 [1907].

Villa Rojas, A. Los Lacandones: recursos económicos y organización social. América Indígena, 27(3), 461-493, 1967. 